\title{
DcR3-TL1A signalling inhibits cytokine-induced proliferation of rheumatoid synovial fibroblasts
}

\author{
MASAYASU TAKAHASHI ${ }^{1}$, YASUSHI MIURA ${ }^{1,2}$, SHINYA HAYASHI $^{1}$, KOJI TATEISHI ${ }^{1}$, \\ KOJI FUKUDA $^{1}$ and MASAHIRO KUROSAKA ${ }^{1}$ \\ ${ }^{1}$ Department of Orthopaedic Surgery, Kobe University Graduate School of Medicine, Chuo-ku, Kobe 650-0017; \\ ${ }^{2}$ Department of Rehabilitation Science, Kobe University Graduate School of Health Sciences, Suma-ku, Kobe 654-0142, Japan
}

Received February 7, 2011; Accepted March 23, 2011

DOI: $10.3892 / \mathrm{ijmm} .2011 .687$

\begin{abstract}
Decoy receptor 3 (DcR3), a member of the tumour necrosis factor receptor (TNFR) superfamily, lacks the transmembrane domain of conventional TNFRs in order to be a secreted protein. DcR3 competitively binds and inhibits members of the TNF family, including Fas ligand (FasL), LIGHT and TL1A. We previously reported that TNF $\alpha$-induced DcR3 overexpression in rheumatoid synovial fibroblasts (RA-FLS) protects the cells from Fas-induced apoptosis and that DcR3 induces VLA-4 expression in THP-1 macrophages to inhibit cycloheximide-induced apoptosis. Meanwhile, recent studies have suggested that DcR3 acting as a ligand directly induces the differentiation of macrophages to osteoclasts. Therefore, in the present study, we analyzed the direct effects of DcR3 as a ligand in RA-FLS. The experiments showed that DcR3 binds to TL1A expressed in RA-FLS resulting in the negative regulation of cell proliferation induced by inflammatory cytokines. DcR3-TL1A signalling may be involved in the pathogenesis of rheumatoid arthritis (RA).
\end{abstract}

\section{Introduction}

Rheumatoid arthritis (RA) is an inflammatory joint disease characterized by hyperplasia of the synovial tissue and formation of pannus, which grow invasively into the cartilage, causing cartilage and bone destruction. Analyses of hyperplastic synovial tissues of patients with RA have revealed a number of features of transformed long-living cells, such as the presence of somatic mutations, expression of oncogenes, and resistance to apoptosis (1-3).

We recently reported that the decoy receptor 3 (DcR3)/ TR6/M68/TNFRSF6b is expressed in rheumatoid fibroblastlike synoviocytes (RA-FLS), and that DcR3 expression induced

Correspondence to: Dr Yasushi Miura, Department of Orthopaedic Surgery, Kobe University Graduate School of Medicine, 7-5-1 Kusunoki-cho, Chuo-ku, Kobe 650-0017, Japan

E-mail: miura@kobe-u.ac.jp

Key words: decoy receptor 3, TL1A, reverse signalling, rheumatoid synovial fibroblast in RA-FLS by TNF $\alpha$ protected the cells from Fas-induced apoptosis (4). DcR3, a member of the tumour necrosis factor receptor (TNFR) superfamily, lacks the transmembrane domain of conventional TNFRs to be a secreted protein (5). DcR3 is typically overexpressed in tumour cells, including lung and colon cancers (5), gliomas, gastrointestinal tract tumours (6) and virus-associated leukaemia (7). In addition, DcR3 is expressed in some normal tissues, including the colon, stomach, spleen, lymph nodes, spinal cord, pancreas and lungs $(5,6)$. However, DcR3 is not expressed in human fibroblast NIH3T3 cells (8). DcR3 has three ligands, i.e., the Fas ligand (FasL), LIGHT and TL1A, all members of the TNF superfamily (9). Overexpression of DcR3 may benefit tumours by helping them to avoid the cytotoxic and regulatory effects of FasL (5), LIGHT (10) and TL1A (11). We suggest that DcR3 is one of the key molecules that regulate the proliferation of RA-FLS (4).

Recent studies have suggested that DcR3 directly induces osteoclast formation from monocytes (12), and that DcR3 triggers enhanced adhesion of monocytes via reverse signalling (13). However, it remains unclear whether DcR3 directly affects RA-FLS proliferation. Further, the molecules interacting with DcR3 for reverse signalling remain unknown. Meanwhile, it has been reported that the DcR3 ligand proteins, FasL, LIGHT and TL1A, are all expressed in RA-FLS (14-16). Therefore, in this study, we analyzed the effects of DcR3 as a ligand on RA-FLS and investigated the possible receptors for DcR3. Our goal was to investigate the role of DcR3 signalling in the pathogenesis of RA.

\section{Materials and methods}

Isolation and culture of fibroblast-like synoviocytes. RA-FLS were obtained during total knee replacement surgery from 20 patients with RA who fulfilled the criteria of the American College of Rheumatology (formerly the American Rheumatism Association) (17). Samples were collected in accordance with the World Medical Association Declaration of Helsinki Ethical Principles for Medical Research Involving Human Subjects. Tissue specimens were minced and digested in Dulbecco's modified Eagle's medium (DMEM; Gibco-BRL, Grand Island, NY) containing $0.2 \%$ collagenase (Sigma, St. Louis, $\mathrm{MO})$ for $2 \mathrm{~h}$ at $37^{\circ} \mathrm{C}$. Dissociated cells were cultured in DMEM 
supplemented with $10 \%$ fetal bovine serum (FBS; BioWhittaker, Walkersville, MD) and $100 \mathrm{U} / \mathrm{ml}$ of penicillin/ streptomycin. After overnight culture, non-adherent cells were removed, and adherent cells were incubated further in fresh medium. All experiments were conducted using cells from passages 3-6 (4).

Proliferation assay. RA-FLS were seeded in 96-well plates at a density of $5 \times 10^{3}$ cells/well in DMEM supplemented with $10 \%$ FBS and cultured for $24 \mathrm{~h}$. The medium was then replaced with serum-free Opti-MEM medium (Gibco-BRL) and the cells were incubated with 10,100 or $1000 \mathrm{ng} / \mathrm{ml}$ of DcR3-Fc, or $1000 \mathrm{ng} / \mathrm{ml}$ of human IgG1 (R\&D Systems, Minneapolis, MN) as a control to eliminate the effects of the Fc protein. Cells were also incubated with or without $1.0 \mathrm{ng} / \mathrm{ml}$ recombinant human TNF $\alpha$ or $0.5 \mathrm{ng} / \mathrm{ml}$ recombinant human IL-1 $\beta$ (R\&D Systems) in the presence of $100 \mathrm{ng} / \mathrm{ml}$ antihuman FasL (anti-FasL) mouse monoclonal Ab, $5.0 \mu \mathrm{g} / \mathrm{ml}$ anti-human LIGHT (anti-LIGHT) mouse monoclonal $\mathrm{Ab}$, $5.0 \mu \mathrm{g} / \mathrm{ml}$ anti-human TL1A (anti-TL1A) mouse monoclonal $\mathrm{Ab}$ (Biolegend, San Diego, CA), or mouse IgG (Acris, Littleton, $\mathrm{CO})$ as a control. Cell proliferation was assessed using the Cell Counting Kit-8 (WST assay, Dojindo, Kumamoto, Japan) (18-19). Values corresponding to the number of viable cells were read at OD $450 \mathrm{~nm}$ with a microplate reader (BioTek Instruments, Winooski, VT).

Western blotting. RA-FLS ( $3 \times 10^{5}$ cells/well) were stimulated with $1.0 \mu \mathrm{g} / \mathrm{ml}$ DcR3-Fc or IgG1 for 0, 0.5, 2 and 5 min after overnight pre-incubation with $5.0 \mu \mathrm{g} / \mathrm{ml}$ anti-TL1A Ab or IgG. After stimulation, cells were washed twice with ice-cold phosphate-buffered saline (PBS) and subsequently lysed on ice for $20 \mathrm{~min}$ in hypotonic lysis buffer ( $25 \mathrm{mM}$ Tris, $1 \% \mathrm{NP}-40$, $150 \mathrm{mM} \mathrm{NaCl}, 1.5 \mathrm{mM}$ EGTA) supplemented with a protease inhibitor and phosphatase inhibitor mix (Roche Diagnostics, Basel, Switzerland). The lysates were centrifuged at 20,000 x g for $12 \mathrm{~min}$ to remove cellular debris and the supernatants were collected. Cytoplasmic proteins were quantified by the Bradford method using the Bio-Rad protein assay reagent (Bio-Rad, Hercules, CA). Each sample was then diluted to an equal concentration with hypotonic lysis buffer. Each sample was diluted to an equal concentration and electrophoresed on a $7.5-15 \%$ polyacrylamide gradient gel (Biocraft, Tokyo, Japan), and electrically transblotted onto blotting membrane (Amersham Biosciences, Arlington Heights, IL).

The expression of phospho-ERK, ERK, phospho-p38 mitogen-activated protein kinase (MAPK), or p38 MAPK was detected using mouse anti-human phospho-ERK Ab, rabbit anti-human ERK Ab, rabbit anti-human phospho-p38 MAPK $\mathrm{Ab}$, or rabbit anti-human p38 MAPK Ab (Cell Signaling Technology, Beverly, MA). Horseradish peroxidase (HRP)conjugated donkey anti-rabbit or sheep anti-mouse IgG Abs (GE Healthcare) were used as secondary antibodies, and the signals were visualized with the ECL plus reagent (GE Healthcare) using the Chemilumino analyzer, LAS-3000 mini (FujiFilm, Tokyo, Japan). Protein expression was assessed by semi-quantification of digitally captured images using the public domain NIH Image program (developed at the US National Institutes of Health and available at http://rsb.info. nih.gov/nih-image/).Protein expression values were normalized

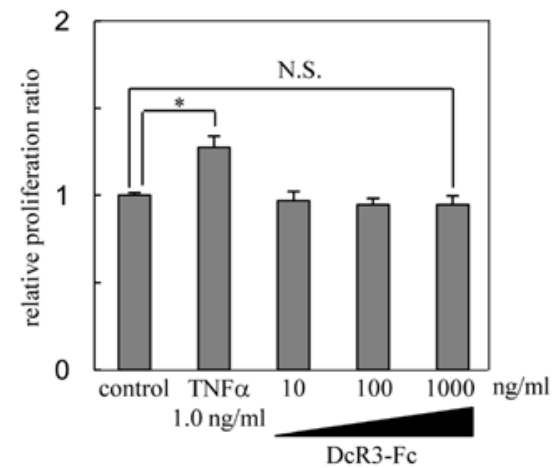

Figure 1. RA-FLS were incubated with 10, 100 or $1000 \mathrm{ng} / \mathrm{ml}$ of DcR3-Fc or $1.0 \mathrm{ng} / \mathrm{ml}$ of $\mathrm{TNF} \alpha$ as a positive control. After $24 \mathrm{~h}$, the proliferation rates were determined by the WST assay. Values are presented as the mean of 10 individual samples per group; untreated cells were assigned a value of 1 . ${ }^{*} \mathrm{P}<0.05$.

to the expression values of the non-phosphorylated forms of p38 and ERK.

Quantification of FasL, LIGHT and TLIA mRNA expression. RNA was extracted from RA-FLS (1x10 cells/well) using the QIAshredder and RNeasy mini kits (Qiagen, Hilden, Germany) according to the manufacturer's protocols. Total RNA $(1 \mu \mathrm{g})$ was reverse-transcribed to first-strand cDNA at $42^{\circ} \mathrm{C}$ for 60 min with $1.25 \mu \mathrm{M}$ oligo(dT) primer in $40 \mu \mathrm{l}$ of PCR buffer II containing $2.5 \mathrm{mM} \mathrm{MgC1}{ }_{2}, 0.5 \mathrm{mM}$ dNTP mix, 0.5 units RNase inhibitor, and 1.25 units MuLV reverse transcriptase (Perkin-Elmer, Foster City, CA). The relative expression levels of mRNAs encoding FasL, LIGHT and TL1A in RA-FLS were compared using TaqMan ${ }^{\circledR}$ real-time PCR on a StepOne ${ }^{\mathrm{TM}}$ real-time PCR system (Applied Biosystems, Foster City, CA). Pre-designed primers and probes for FasL, LIGHT, TL1A and glyceraldehyde-3-phosphate dehydrogenase (GAPDH) as the control were obtained from Applied Biosystems.

Statistical analysis. All data are expressed as the mean \pm SD unless otherwise indicated. ANOVA and Dunnett's tests were used to assess the statistical significance of the differences.

\section{Results}

$D c R 3-F c$ inhibits the proliferation induced by TNF $\alpha$ or $I L-1 \beta$. Proliferation assay results indicated that DcR3-Fc alone did not affect RA-FLS proliferation (Fig. 1). However, DcR3-Fc significantly inhibited the proliferation induced by $1.0 \mathrm{ng} / \mathrm{ml}$ $\mathrm{TNF} \alpha$ in a dose-dependent manner $(24.6 \%$ inhibition at $100 \mathrm{ng} / \mathrm{ml}$ and $56.3 \%$ inhibition at $1000 \mathrm{ng} / \mathrm{ml}$ ) (Fig. 2A). Similarly, DcR3-Fc significantly inhibited the proliferation induced by $0.5 \mathrm{ng} / \mathrm{ml} \mathrm{IL-1 \beta}$ (34.4\% inhibition at $100 \mathrm{ng} / \mathrm{ml}$ and $58.6 \%$ inhibition at $1000 \mathrm{ng} / \mathrm{ml}$ ) (Fig. 2B).

TL1A mRNA is the predominant mRNA of DcR3-specific ligands expressed in RA-FLS. To identify the expression of FasL, LIGHT and TL1A in RA-FLS, mRNA levels of the TNFs were quantified by real-time PCR, which allows the direct monitoring of amplicon accumulation during the PCR process using fluorogenic probes, providing fluorescence kinetics that accurately reflect the levels of cytokine mRNAs in biological 
A

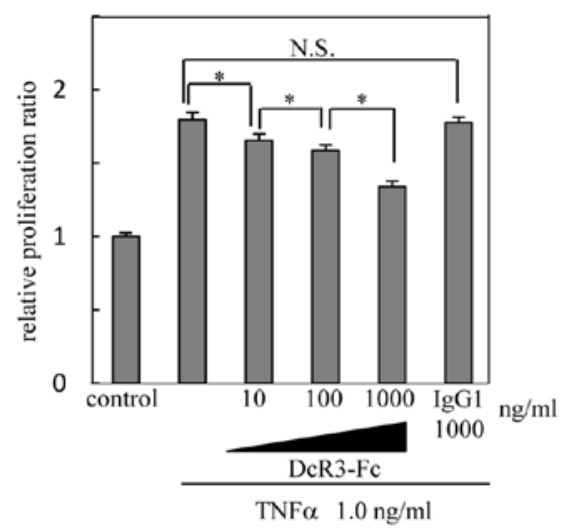

B

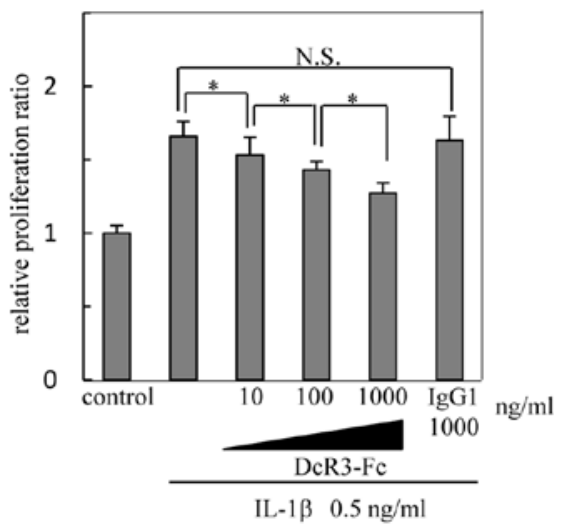

Figure 2. RA-FLS were incubated with 10,100 or $1000 \mathrm{ng} / \mathrm{ml} \mathrm{DcR3-Fc} \mathrm{or} 1000 \mathrm{ng} / \mathrm{ml}$ IgG1 in the presence of (A) $1.0 \mathrm{ng} / \mathrm{ml} \mathrm{TNF} \alpha$ or with (B) $0.5 \mathrm{ng} / \mathrm{ml} \mathrm{IL}-1 \beta$. After $24 \mathrm{~h}$, the proliferation rates were determined by the WST assay. Values are presented as the mean of 10 individual samples per group; untreated cells were assigned a value of $1 .{ }^{*} \mathrm{P}<0.05$.

samples (20-21). All three genes were expressed, however, the relative expression levels varied among the genes with the expression of TL1A being the highest, followed by LIGHT and FasL (Fig. 3).

Anti-TL1A antibody negates the inhibitory effect of DcR3-Fc on RA-FLS proliferation induced by TNF $\alpha$ or $I L-1 \beta$. The inhibitory effect of DcR3-Fc on the proliferation of RA-FLS stimulated with TNF $\alpha$ or IL-1 $\beta$ was significantly suppressed when the cells were pre-treated with anti-TL1A Ab (Fig. 4C and $\mathrm{F}$ ), but not when they were pre-treated with anti-LIGHT $\mathrm{Ab}$ (Fig. 4B and E) or anti-FasL Ab (Fig. 4A and D).

Anti-TL1A antibody ablates the activation of ERK and p38MAPK signalling in RA-FLS induced by DcR3-Fc. Western blotting revealed that $\mathrm{p} 38 \mathrm{MAPK}$ signalling increased 3.75- and 3.47-fold of the control value following treatment with $1.0 \mu \mathrm{g} / \mathrm{ml}$ of DcR3-Fc for 0.5 and $2 \mathrm{~min}$, respectively (Fig. 5A). ERK signalling increased 3.11-fold with treatment for $0.5 \mathrm{~min}$ and 4.86-fold with treatment for $2 \mathrm{~min}$ (Fig. 5B). Pre-treatment with anti-TL1A Ab at $5.0 \mu \mathrm{g} / \mathrm{ml}$ negated the DcR3-Fc-mediated activation of p38MAPK and ERK in RA-FLS, but pre-treatment with IgG had no effect (Fig. 5).

\section{Discussion}

RA is a systemic autoimmune disorder characterized by synovial tissue hyperplasia with infiltration of various inflammatory cells that leads to cartilage and bone destruction (22). Nevertheless, the abnormal proliferation of synoviocytes is not limitless, and spontaneous remission of synovial proliferation has been observed (23-25).

We recently demonstrated that DcR3 acts as a decoy receptor (4) protecting RA-FLS cells from Fas-induced apoptosis, and that DcR3 also functions as a ligand to inhibit apoptosis in THP-1 macrophages by increasing VLA-4 expression (26). Several studies have reported that soluble DcR3 activates reverse signalling as a ligand, inducing osteoclast formation from monocytes/macrophages $(12,27)$, as well as inducing actin reorganization and enhancing adhesion of monocytes (13), and inducing dendritic cell apoptosis by activating

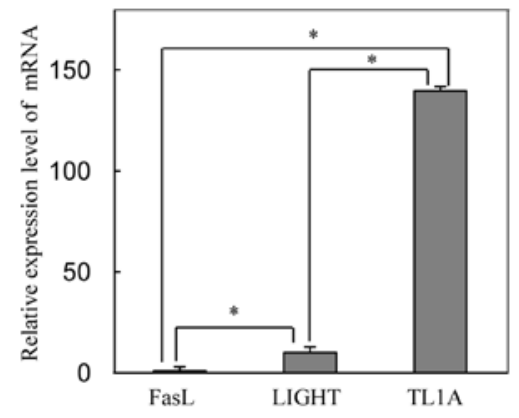

Figure 3. Real-time PCR analysis of FasL, LIGHT and TL1A mRNA expression in RA-FLS. Values were normalized to GAPDH mRNA expression. The relative expression ratios of each mRNA were compared to FasL. The data are the mean of 12 individual samples per group. ${ }^{*} \mathrm{P}<0.05$.

PKC- $\delta$ and JNK (28-29). However, to date no studies have addressed RA-FLS.

In the present study, we demonstrated that DcR3-Fc inhibits the proliferation of RA-FLS induced by TNF $\alpha$ or IL-1 $\beta$. The DcR3-Fc fusion protein has been shown to have a similar binding affinity and specificity as DcR3 (30). In our experiments control IgG1 had no effect on RA-FLS. Our results therefore, are the first to suggest that DcR3 may negatively regulate the cytokine-induced proliferation of RA-FLS.

In addition, we showed that TL1A mRNA is dominantly expressed among the three DcR3 ligands in RA-FLS. It is reported that mRNA expression of cytokines quantified by real-time PCR correlates well with the protein levels (20-21). Therefore, TL1A protein is postulated to be dominantly expressed among the DcR3 specific ligands in RA-FLS. Of course, the quantities of mRNA do not directly reflect the activities of proteins, however, a certain level of mRNA expression is required for the functioning protein expression.

Indeed, we have demonstrated that anti-TL1A Ab abolishes the inhibitory effect of DcR3-Fc on the proliferation of RA-FLS induced by TNF $\alpha$ or IL- $1 \beta$, but the anti-LIGHT Ab or the anti-FasL Ab did not. We also revealed that anti-TL1A $\mathrm{Ab}$ negates the activation of ERK and p38MAPK signalling in RA-FLS. These results suggest that DcR3 may interact with TL1A expressed on the surface of RA-FLS. In other words, 

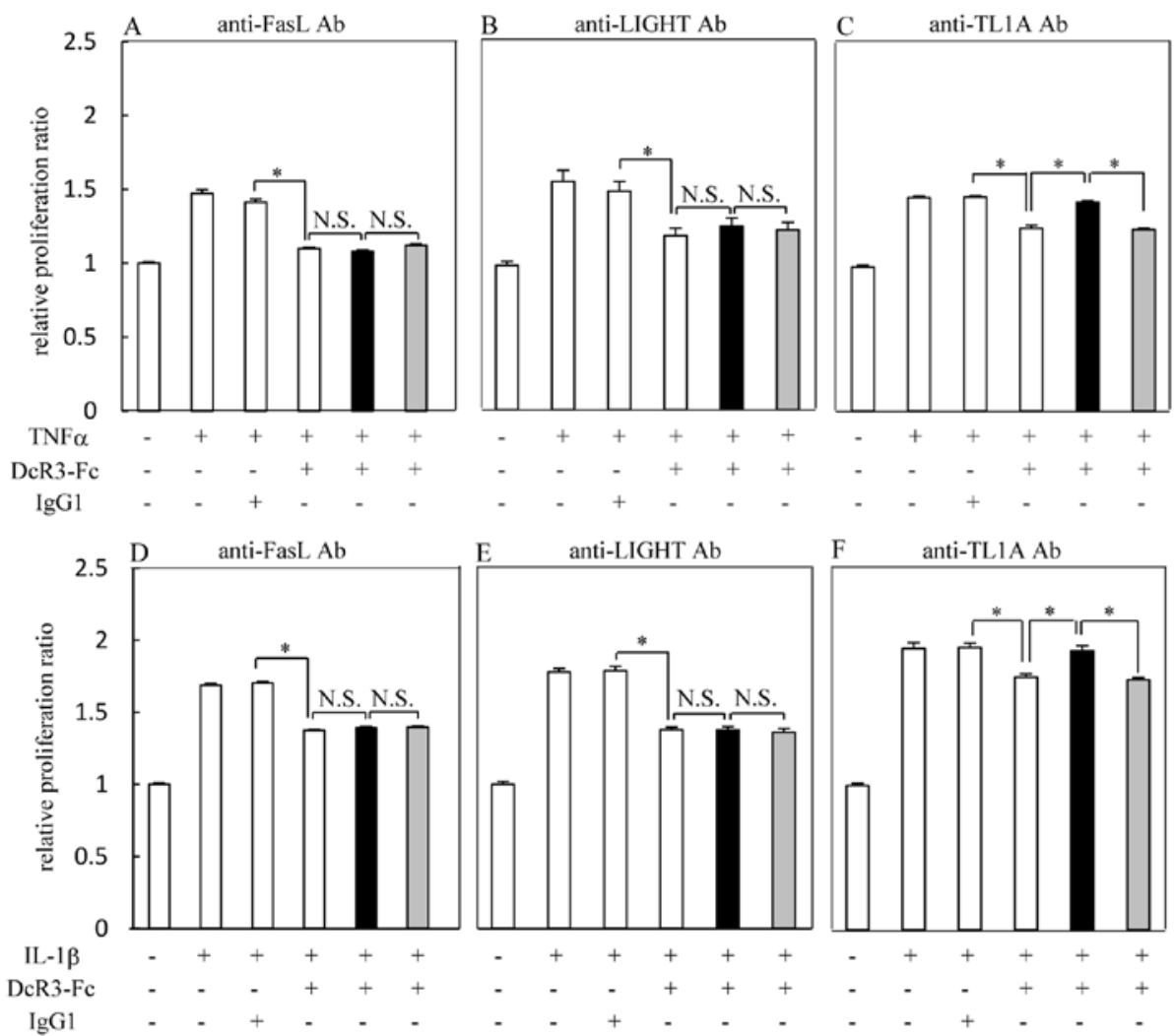

Figure 4. RA-FLS were pre-incubated overnight with $100 \mathrm{ng} / \mathrm{ml}$ anti-FasL Ab (black bars in A and D), $5.0 \mu \mathrm{g} / \mathrm{ml}$ anti-LIGHT Ab (black bars in B and E), $5.0 \mu \mathrm{g} / \mathrm{ml}$ anti-TL1A Ab (black bars in C and F), or IgG as control (gray bars). The culture medium was replaced with Opti-MEM and the cells were incubated for $24 \mathrm{~h}$ with $1.0 \mu \mathrm{g} / \mathrm{ml}$ DcR3-Fc or $1.0 \mu \mathrm{g} / \mathrm{ml} \mathrm{IgG1}$ with or without $1.0 \mathrm{ng} / \mathrm{ml} \mathrm{TNF} \alpha$ or $0.5 \mathrm{ng} / \mathrm{ml} \mathrm{IL}-1 \beta$. The results are the mean of 10 individual experiments. ${ }^{*} \mathrm{P}<0.05$.
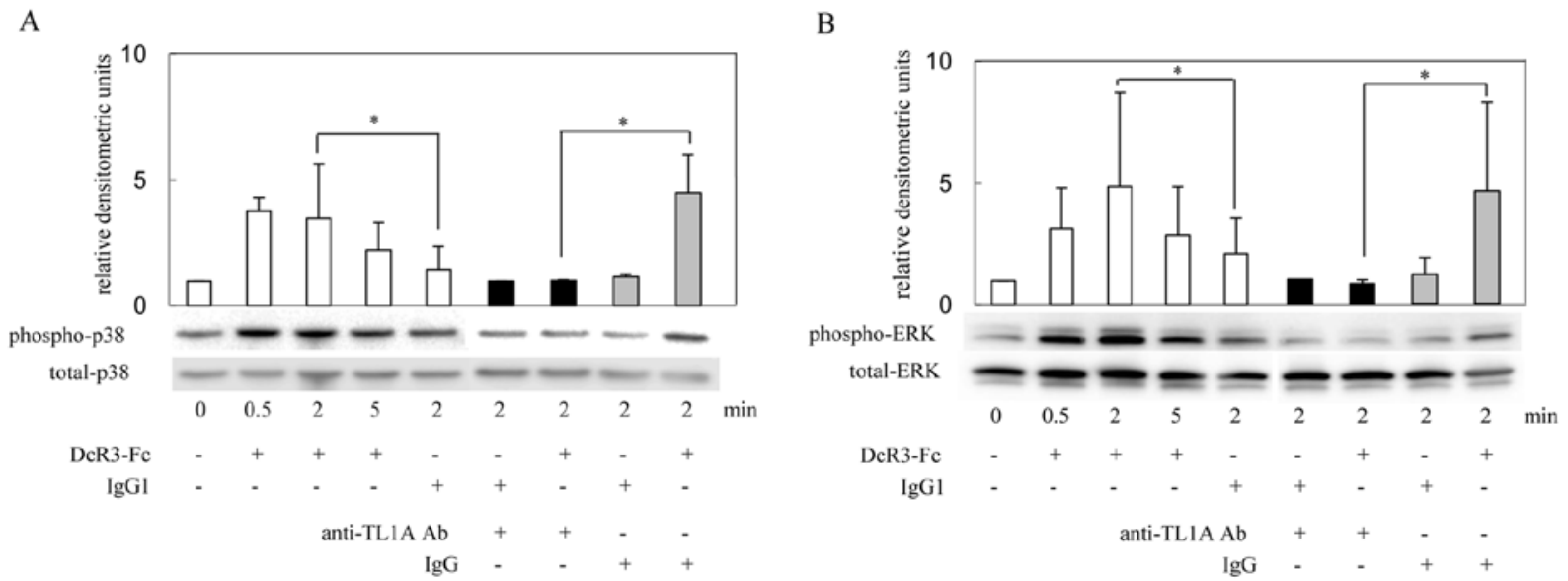

Figure 5. RA-FLS were stimulated with $1.0 \mu \mathrm{g} / \mathrm{ml} \mathrm{DcR} 3-\mathrm{Fc}$ or IgG1 for $0,0.5,2$ and 5 min after overnight pre-incubation with $5.0 \mu \mathrm{g} / \mathrm{ml}$ anti-TL1A Ab (black bars) or IgG (gray bars). (A) p38MAPK signalling and (B) ERK signalling are shown. The Western blotting photograph is a representative of five independent experiments. ${ }^{~} \mathrm{P}<0.05$.

DcR3 may act as an inducer, and membrane-bound TL1A may act as a receptor in RA-FLS. Furthermore, it has been reported that the severe stage of RA is associated with highly elevated serum levels of TL1A and DcR3, suggesting that TL1A, death receptor 3 (DR3), a specific receptor of TL1A and one of the death receptors belonging to TNFR (11), and DcR3-mediated pathways may be involved in the pathogenesis of RA (31). These results suggest a robust association of DcR3 with TL1A.
A number of recent studies have illustrated the functions of TL1A in autoimmune diseases, including inflammatory bowel diseases (IBD) and RA (14,31-36). Consistent with the role of TNF in inducing the release of TL1A, serum TL1A levels have been shown to substantially decrease in RA patients treated with adalimumab, an anti-TNF monoclonal Ab (31), indicating that TL1A has a role in the progression rather than induction of the disease (36). Treatment with an antagonistic anti-TL1A monoclonal antibody protected animals with collagen-induced 
arthritis, a systemic disease model of RA (33). Therapeutic strategies can therefore be envisaged that use TNF inhibitors in combination with either anti-TL1A antibodies or soluble DR3 protein (36). Furthermore, by acting as a decoy receptor, DcR3 can interfere with TL1A-DR3-mediated inflammatory responses and protect joint tissue from apoptosis induced by TNF superfamily ligands (36). However, DcR3 may also contribute to the pathogenesis of RA by down-regulating the apoptotic pathways of inflammatory cells (4). In addition, the death receptors including DR3 have reciprocal functions. i.e., inducing apoptosis and activating NF- $\mathrm{B}$ (11).

In conclusion, not only by inhibiting Fas-induced apoptosis as a decoy receptor, but also by inhibiting cell proliferation directly via TL1A, DcR3 plays a critical role in the pathogenesis of RA. However, many details regarding how DcR3-TL1A functions in autoimmune diseases have not been elucidated. Further studies of this network will be helpful in developing better strategies for the treatment of RA.

\section{Acknowledgements}

The authors wish to thank Ms. Kyoko Tanaka, Minako Nagata and Maya Yasuda for technical assistance. This study is supported by a grant-in-aid from the Health Science Research Grant from the Ministry of Health and Welfare of Japan (no. 21591944).

\section{References}

1. Chou CT, Yang JS and Lee MR: Apoptosis in rheumatoid arthritis - expression of Fas, Fas-L, p53, and Bcl-2 in rheumatoid synovial tissues. J Pathol 193: 110-116, 2001.

2. Tak PP, Zvaifler NJ, Green DR and Firestein GS: Rheumatoid arthritis and p53: how oxidative stress might alter the course of inflammatory diseases. Immunol Today 21: 78-82, 2000.

3. Yamanishi Y, Boyle DL, Rosengren S, Green DR, Zvaifler NJ and Firestein GS: Regional analysis of p35 mutations in rheumatoid arthritis synovium. Proc Natl Acad Sci USA 99: 10025-10030, 2002.

4. Hayashi S, Miura Y, Nishiyama T, et al: Decoy receptor 3 expressed in rheumatoid synovial fibroblasts protects the cells against Fas-induced apoptosis. Arthritis Rheum 56: 1067-1075, 2007.

5. Pitti RM, Marsters SA, Lawrence DA, et al: Genomic amplification of a decoy receptor for Fas ligand in lung and colon cancer. Nature 396: 699-703, 1998.

6. Bai C, Connolly B, Metzker ML, et al: Overexpression of M68/ DcR3 in human gastrointestinal tract tumors independent of gene amplification and its location in a four-gene cluster. Proc Natl Acad Sci USA 97: 1230-1235, 2000.

7. Ohshima K, Haraoka S, Sugihara M, et al: Amplification and expression of a decoy receptor for Fas ligand (DcR3) in virus (EBV or HTLV-I) associated lymphomas. Cancer Lett 160: 89-97, 2000.

8. Chen JG, Zhang LR and Kim S: Quantification and detection of DcR3, a decoy receptor in TNFR family. J Immun Methods 285: 63-70, 2004

9. Shi G, Wu Y, Zhang J and Wu J: Death decoy receptor TR6/ DcR3 inhibits T cell chemotaxis in vitro and in vivo. J Immunol 171: 3407-3414, 2003.

10. Yu KY, Kwon B, Ni J, Zhai YF, Ebner R and Kwon BS: A newly identified member of tumor necrosis factor receptor superfamily (TR6) suppresses LIGHT-mediated apoptosis. J Biol Chem 274: 13733-13736, 1999.

11. Migone TS, Zhang J, Luo X, et al: TL1A is a TNF-like ligand for DR3 and TR6/DcR3 and functions as a T cell costimulator. Immunity 16: 479-492, 2002.

12. Yang CR, Wang JH, Hsieh SL, Wang SM, Hsu TL and Lin WW: Decoy receptor 3 (DcR3) induces osteoclast formation from monocyte/macrophage lineage precursor cells. Cell Death Differ 11 (Suppl 1): S97-S107, 2004.
13. Hsu MJ, Lin WW, Tsao WC, et al: Enhanced adhesion of monocytes via reverse signaling triggered by decoy receptor 3 . Exp Cell Res 292: 241-251, 2004.

14. Cassatella MA, Pereira-da-Silva G, Tinazzi I, et al: Soluble TNF-like cytokine (TL1A) production by immune complexes stimulated monocytes in rheumatoid arthritis. J Immunol 178: 7325-7333, 2007.

15. Kim WJ, Kang YJ, Koh EM, Ahn KS, Cha HS and Lee WH: LIGHT is involved in the pathogenesis of rheumatoid arthritis by inducing the expression of pro-inflammatory cytokines and MMP-9 in macrophages. Immunology 114: 272-279, 2005.

16. Telegina E, Reshetnyak T, Moshnikova A, et al: A possible role of Fas-ligand-mediated 'reverse signaling' in pathogenesis of rheumatoid arthritis and systemic lupus erythematosus. Immunol Lett 122: 12-17, 2009.

17. Arnett FC, Edworthy SM, Bloch DA, et al: The American Rheumatism Association 1987 revised criteria for the classification of rheumatoid arthritis. Arthritis Rheum 31: 315-324, 1988

18. Ishiyama M, Miyazono Y, Sasamoto K, Ohkura Y and Ueno K: A highly water-soluble disulfonated tetrazolium salt as a chromogenic indicator for NADH as well as cell viability. Talanta 44: 1299-1305, 1997.

19. Maekawa Y, Yagi K, Nonomura A, et al: A tetrazolium-based colorimetric assay for metabolic activity of stored blood platelets. Thromb Res 109: 307-314, 2003.

20. Rioja I, Bush KA, Buckton JB, Dickson MC and Life PF: Joint cytokine quantification in two rodent arthritis models: kinetics of expression, correlation of mRNA and protein levels and response to prednisolone treatment. Clin Exp Immunol 137: 65-73, 2004.

21. Overbergh L, Giulietti A, Valckx D, Decallonne R, Bouillon R and Mathieu C: The use of real-time reverse transcriptase PCR for the quantification of cytokine gene expression. J Biomol Tech 14: 33-43, 2003.

22. Harris ED Jr: Rheumatoid arthritis. Pathophysiology and implications for therapy. N Engl J Med 322: 1277-1289, 1990.

23. Nakajima T, Aono H, Hasunuma $\mathrm{T}$, et al: Apoptosis and functional Fas antigen in rheumatoid arthritis synoviocytes. Arthritis Rheum 38: 485-491, 1995.

24. Firestein GS, Yeo M and Zvaifler NJ: Apoptosis in rheumatoid arthritis synovium. J Clin Invest 96: 1631-1638, 1995.

25. Hoa TT, Hasunuma T, Aono H, et al: Novel mechanisms of selective apoptosis in synovial T cells of patients with rheumatoid arthritis. J Rheumatol 23: 1332-1337, 1996.

26. Tateishi K, Miura Y, Hayashi S, Takahashi M and Kurosaka M: DcR3 protects THP-1 macrophages from apoptosis by increasing integrin alpha4. Biochem Biophys Res Commun 389: 593-598, 2009.

27. Chang YC, Hsu TL, Lin HH, et al: Modulation of macrophage differentiation and activation by decoy receptor 3. J Leukoc Biol 75: 486-494, 2004

28. You RI, Chang YC, Chen PM, et al: Apoptosis of dendritic cells induced by decoy receptor 3 (DcR3). Blood 111: 1480-1488, 2008.

29. Tang CH, Hsu TL, Lin WW, et al: Attenuation of bone mass and increase of osteoclast formation in decoy receptor 3 transgenic mice. J Biol Chem 282: 2346-2354, 2007.

30. Connolly K, Cho YH, Duan R, et al: In vivo inhibition of Fas ligand-mediated killing by TR6, a Fas ligand decoy receptor. J Pharmacol Exp Ther 298: 25-33, 2001.

31. Bamias G, Siakavellas SI, Stamatelopoulos KS, Chryssochoou E, Papamichael C and Sfikakis PP: Circulating levels of TNF-like cytokine 1A (TL1A) and its decoy receptor 3 (DcR3) in rheumatoid arthritis. Clin Immunol 129: 249-255, 2008.

32. Zhang J, Wang X, Fahmi H, et al: Role of TL1A in the pathogenesis of rheumatoid arthritis. J Immunol 183: 5350-5357, 2009.

33. Bull MJ, Williams AS, Mecklenburgh Z, et al: The death receptor 3-TNF-like protein $1 \mathrm{~A}$ pathway drives adverse bone pathology in inflammatory arthritis. J Exp Med 205: 2457-2464, 2008.

34. Bamias G, Martin C III, Marini M, et al: Expression, localization, and functional activity of TL1A, a novel Th1-polarizing cytokine in inflammatory bowel disease. J Immunol 171: 4868-4874, 2003.

35. Bamias G, Mishina M, Nyce M, et al: Role of TL1A and its receptor DR3 in two models of chronic murine ileitis. Proc Natl Acad Sci USA 103: 8441-8446, 2006.

36. Bayry J: Immunology: TL1A in the inflammatory network in autoimmune diseases. Nat Rev Rheumatol 6: 67-68, 2010. 